\section{Knowledge of obstetric danger signs among pregnant women attending antenatal clinic in Murtala Muhammad Specialist Hospital, Kano, Nigeria}

\author{
Ayyuba Rabiu, ${ }^{1}$ Habiba Isah Ladu ${ }^{2}$ \\ ${ }^{1}$ Department of Obstetrics and \\ Gynecology, Bayero University \\ Kano/Aminu Kano Teaching Hospital, \\ Kano; ${ }^{2}$ Department of Obstetrics and \\ Gynecology, Aminu Kano Teaching \\ Hospital, Kano, Kano State, Nigeria
}

\begin{abstract}
Knowledge of obstetric danger sign promotes active preparation and decision making for delivery by pregnant women and their families. It assists in decision making for seeking health care in case of complications. This study was aimed at determining the knowledge of obstetric danger signs among pregnant women attending antenatal clinic in Murtala Muhammad specialist hospital Kano. It was a cross sectional survey among 394 pregnant women attending antenatal clinic. Information on knowledge of obstetric danger signs were recorded on a questionnaire. The data were analyzed using SPSS version 19 Computer Software (IBM SPSS
\end{abstract} Statistics Inc., IL, Chicago USA). Quantitative variables were summarized using measures of central tendency and measures of variability. Qualitative variables were summarized using frequencies and percentages. A P value of $\leq 0.05$ was considered statistically significant. The mean age \pm SD was $26.9 \pm 6.21$ years. The mean gestational age at booking was $29.7 \pm 7.22$ weeks. Two hundred and eightysix $(77.1 \%)$ Pregnant women were aware that unforeseen problems related to pregnancy can occur during any pregnancy that can endanger the life of the woman. These problems include bleeding $176(61.6 \%)$ and convulsion 96 (33.6\%). Should any of those problems occur, a woman should preferably visit government hospital 366 (92.9\%). Concerning danger signs of pregnancy, the respondents mentioned that a health worker advised them at least once, about danger signs of serious health problems during pregnancy, child birth or soon after 228 $(63.3 \%)$. The study findings generally revealed that there was awareness of obstetrics danger signs. Vaginal bleeding was the commonest obstetric danger sign known. Knowledge of obstetric danger signs was statistically associated with parity and age group.

\section{Introduction}

Obstetric danger signs are symptoms of obstetric complication(s) reported by a woman during pregnancy, delivery, or within 6 weeks after delivery. ${ }^{1}$ The commonest danger signs during pregnancy include severe vaginal bleeding, swollen hands/face, and blurred vision. Danger signs during labor and child birth include severe vaginal bleeding, prolonged labor, convulsions, and retained placenta. Danger signs during the post-partum period include severe bleeding following child birth, loss of consciousness after child birth, and fever. $^{2}$

Inadequacy or lack of knowledge of obstetric danger signs is one of the several factors contributing to maternal death. Knowledge of obstetric danger signs is an integral component of focused antenatal care which involves planning with the health care provider, pregnant women, relatives, and the community. ${ }^{3}$ Knowledge of obstetric danger is an approach that aims at raising awareness at community level and creating a stronger demand for quality health services. Since pregnancy is perceived as an ordinary event by many, most families do not plan for birth, nor do they expect any complication to arise. Reports have shown that in most instances, women and their families do not recognize danger signs of pregnancy and when they occur, the unprepared family wastes a great deal of time in recognizing the problem, obtaining funds, locating transport and reaching the appropriate health facility. ${ }^{4}$ Thus, it is important that all pregnant women and their families are well informed about the obstetric danger signs and what action should be taken. Knowledge of obstetric danger signs is a safe motherhood strategy which addresses delays that could lead to death of a mother during pregnancy, child birth or immediate post-partum period. The strategy has not been effective in Nigeria, hence, maternal mortality remains unacceptably high, and thus, the challenge of improving maternal survival is still enormous.

The purpose of the study was to determine the knowledge of obstetric danger signs, among pregnant women attending antenatal clinic in Murtala Muhammad specialist hospital (MMSH), Kano.

\section{Operational definition}

Danger signs: In this study refers to manifestations of obstetric complications that are easily identified by non-clinical per-
Correspondence: Ayyuba Rabiu, Department of Obstetrics and Gynecology, Bayero University Kano/Aminu Kano Teaching Hospital, PMB 3011, Kano State, Nigeria.

Tel.: 08055559473.

E-mail: ayyubarabiu@yahoo.com

Key words: awareness, obstetric danger signs, ante-natal clinic, Nigeria.

Contributions: the authors contributed equally.

Conflict of interest: the authors declare no potential conflict of interest.

Funding: none.

Received for publication: 10 August 2018. Accepted for publication: 23 April 2019.

This work is licensed under a Creative Commons Attribution NonCommercial 4.0 License (CC BY-NC 4.0).

(C) Copyright: the Author(s), 2019

Licensee PAGEPress, Italy

Pyramid Journal of Medicine 2019; 2:19

doi:10.4081/pjm.2019.19

sonnel and necessitate skilled care during pregnancy, labor, delivery and post-partum.

\section{Materials and Methods}

The study was a descriptive cross sectional, carried out from $12^{\text {th }}$ December 2017 to $31^{\text {st }}$ March 2018 among 394 pregnant women of child bearing age (15-49 years) in the antenatal clinic of Murtala Muhammad Specialist Hospital. Ethical approval was sought and obtained from the Ethics Committee of Kano State Ministry of Health. Data were collected using an interviewer administered questionnaire modified, validated and adopted from a study titled "Monitoring birth preparedness and complication readiness". ${ }^{5} \mathrm{An}$ informed consent was sought and obtained from all the eligible pregnant women. A systematic sampling method was used to select the pregnant women until the desired sample size was obtained. Information such as socio demographic characteristics, knowledge of obstetric danger signs was recorded on the questionnaire. The data collected were analyzed using SPSS version 19 Computer Software (IBM SPSS Statistics Inc., IL, Chicago USA). Quantitative variables were summarized using measures of central tendency and measures of variability. Qualitative variables were summarized using frequencies and percentages. A P value of $\leq 0.05$ was considered statistically 
significant.

\section{Results}

Three hundred and ninety-four pregnant women were recruited during the study period (from $12^{\text {th }}$ December 2017 to $31^{\text {st }}$ March 2018). The mean age \pm SD was $26.9 \pm 6.21$ years. The mean parity was $3.4 \pm 2.94$. The mean number of living children was $2.8 \pm 2.6$. The mean gestational age at booking was $29.7 \pm 7.22$ weeks.

Eighty pregnant women (20.4\%) had at least one stillbirth while 60 pregnant women $(15.6 \%)$ had at least one neonatal death.

Two hundred and eighty-six (77.1\%) were knowledgeable of the unforeseen problems related to pregnancy that can occur and endanger the life of the woman. These problems, include bleeding 176 (61.6\%), severe headache 93 (32.5\%), convulsion 96 (33.6\%) and fever 56 (19.6\%). Significant number of the respondents 217 $(76.0 \%)$ also believed a woman could die from these problems (Table 1).

According to the respondents, serious health problems that can endanger the life of the pregnant woman in labor and child birth include convulsion 171 (49.0\%), severe bleeding 144 (41.3\%), severe headache $80(23.0 \%)$ and prolonged labor
$62(17.8 \%)$. Also, 297 (82.5\%) believed a woman could die from any of these problems.

The respondents made mention that serious health problems that could occur and endanger the health of a woman within the first two days after delivery include severe headache 232 (64.4\%), swollen hands/face 184 (51.1\%), severe bleeding 75 (20.8\%) and blurred vision 24 (6.7\%). Should any of the above occur, a woman should preferably visit government hospital $366(92.9 \%)$ and government health center $20(5.1 \%)$.

Majority of the respondents were in the second trimester of pregnancy $265(68.3 \%)$ when they first booked for antenatal care,

Table 1. Knowledge of obstetrics danger sign.

Can unforeseen problems related to pregnancy occur during any pregnancy or child birth that can endanger the life of the woman?

Yes

No

I don't know

Total

$\begin{array}{cc}286 & 77.1 \\ 59 & 16.0 \\ 26 & 6.9 \\ 371 & 100.0\end{array}$

What are those serious health problems that can occur during pregnancy and endanger the life of the woman? $(\mathrm{n}=286)$

Bleeding

Severe headache

Convulsion

High fever

Swollen hands/feet

Others (blurred vision, loss of consciousness, difficulty in breathing, severe weakness, severe abdominal pain, accelerated/reduced fetal movements, water break without labour) *Total

$176 \quad 61.6$

In your opinion, could a woman die from these problems? $(\mathrm{n}=286)$

Yes

No

I don't know

Total

What are some serious health problems that can occur in labor and childbirth that could endanger the life of the woman?

Convulsion

Severe bleeding

Severe headache

Labour lasting more than 12 hours

Retained placenta

High fever

Convulsion

I don't know

*Total

$\begin{array}{cc}171 & 49.0 \\ 144 & 41.3 \\ 80 & 23.0 \\ 62 & 17.8 \\ 32 & 9.2 \\ 45 & 12.9 \\ 65 & 18.6 \\ 24 & 6.9 \\ 623 & 100.0\end{array}$

uld a woman die from any of these problems?

Yes

No

I don't know

Total

What are the serious health problems that can occur during the first 2 days after birth that could endanger the life of the woman?

Severe headache

Swollen hands/face

Severe bleeding

Blurred vision

Convulsion

*Total

623

297

297
31
32

31
32
360

360

232

232
184

184
75

75
24

12

527

82.5

8.6

8.9 100.0

Where should a woman visit when she experiences any of the above danger signs in pregnancy, labour and delivery?

Government hospital

Government health centre

Others ( traditional birth attendant, traditional healers, government dispensary, private hospital) Total

*Response not mutually exclusive.

$\begin{array}{ll}8 & 2.0\end{array}$

394


followed by third trimester $80(20.6 \%)$ and first trimester $41(10.6 \%)$ respectively (Figure 1). They were first seen in the antenatal clinic by health professionals 329 $(89.4 \%)$ and community health workers 27 (7.4\%) (Table 2).

More than half of the respondents 203 $(59.5 \%)$ were aware of their last menstrual period and $25 \%$ of them planned to have less than 4 antenatal visits (Table 2)

Concerning danger signs of pregnancy, the respondents mentioned that a health worker advised them at least once about danger signs of serious health problems during pregnancy, child birth or soon after 228 $(63.3 \%)$; where to go if they have danger signs of serious health problems 236 (64.1\%); where they should give birth 245 $(63.5 \%)$; arrangements for transportation 170 (44.3\%), Funds 186 (48.3\%), blood donor $166(43.3 \%)$ and for the skilled birth attendant that would deliver their babies

\section{7 (57.4\%) (Table 2).}

At least half of the respondent 196 $(50.5 \%)$ spoke with someone outside the health facility about the danger signs of serious health problems during pregnancy, childbirth or soon after; they spoke mainly with husband $156(80.0 \%)$, other family members $25(12.8 \%)$ and friends/neighbors $21(10.7 \%)$. Also, more than half of the respondents $213(55.5 \%)$ spoke with someone outside the health facility about where

Table 2. Personal experiences on current pregnancy.

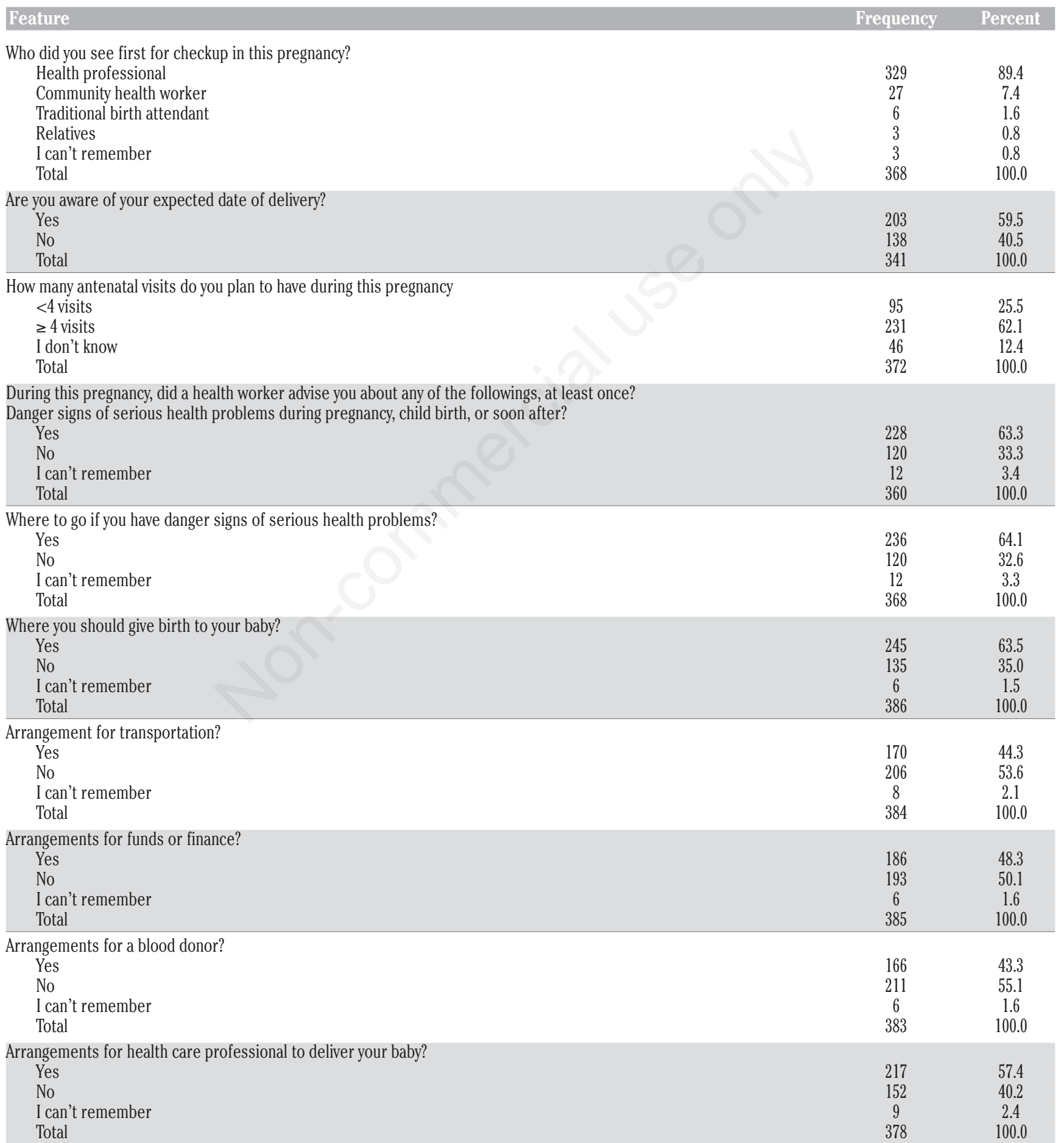


to go when there was a danger sign of serious health problems; they spoke with husband $195(91.5 \%)$, other family members $21(9.9 \%)$, community health worker 11 $(5.2 \%)$ and friend/neighbor 7 (3.3\%) (Table 3 ). The study showed that knowledge of obstetric danger signs was statistically associated with parity and age group $[\chi 2=19.778, \mathrm{P}=0.000 ; \mathrm{P}$ (Fischer's') = 0.017 respectively] (Table 4).

\section{Discussion}

This study was carried out among 394 pregnant women attending ante-natal clinic in Murtala Muhammad Specialist Hospital, Kano from $12^{\text {th }}$ December 2017 to $31^{\text {st }}$ March 2018. More than 20\% of the respondents $(20.4 \%)$ had at least one stillbirth and $15.6 \%$ also experienced a neonatal death.
This shows that a significant proportion of the respondents have experienced a bad obstetric history within their child bearing age. Low patronage of maternal care services, ${ }^{6}$ high rate of home delivery and inadequate number of skilled birth attendants could be attributable to this high rate of perinatal death. Majority of the respondents $(68.3 \%)$ booked for ante-natal clinic in the second trimester; $10.7 \%$ booked in the $1^{\text {st }}$ trimester, while $20.6 \%$ booked for antenatal in the $3^{\text {rd }}$ trimester. A study conducted among pregnant women in Abakaliki, Southeastern Nigeria on pattern and Determinants of Antenatal Booking shows that $16.9 \%(58 / 344)$ booked early (within the first trimester) while $83.1 \%(296 / 344)$ booked late (after the first trimester). ${ }^{7}$ The mean gestational age at booking was $29.7 \pm 7.22$ weeks, which is lower than the gestational age at booking reported in
Sokoto $(23.3 \text { weeks })^{8}$ and Lagos $(23.5$ weeks), ${ }^{9}$ This shows that women in our country usually book for ante-natal late in pregnancy. Lack of knowledge of benefit of early antenatal booking and some degree of

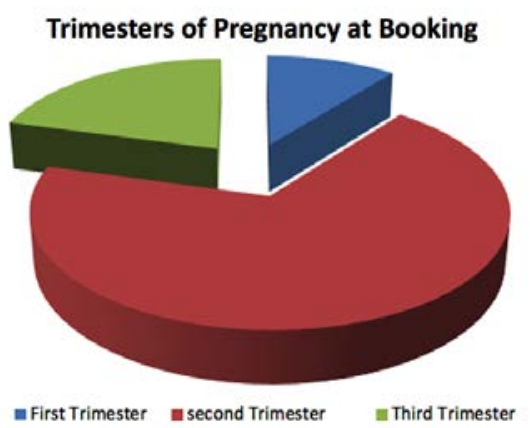

Figure 1. Distribution of the respondents based on trimester of pregnancy.

Table 3. Knowledge based communication about danger signs of pregnancy.

Did you speak with anyone outside health facility about the danger signs of serious health problems during pregnancy, childbirth, or soon after?

\begin{tabular}{lc} 
Yes & 196 \\
No & 191 \\
I can't remember & 1 \\
Total & 39.5 \\
es, Whom did you speak with? (n=196) & 0.3 \\
Husband & 100.0 \\
Other family member & 156 \\
Friend/neighbor & 25 \\
Others (Mother in-law, community health worker) & 80.0 \\
Total & 21 \\
\hline
\end{tabular}

Did you speak with anyone outside health facility about where to go if you have danger signs of serious health problems?

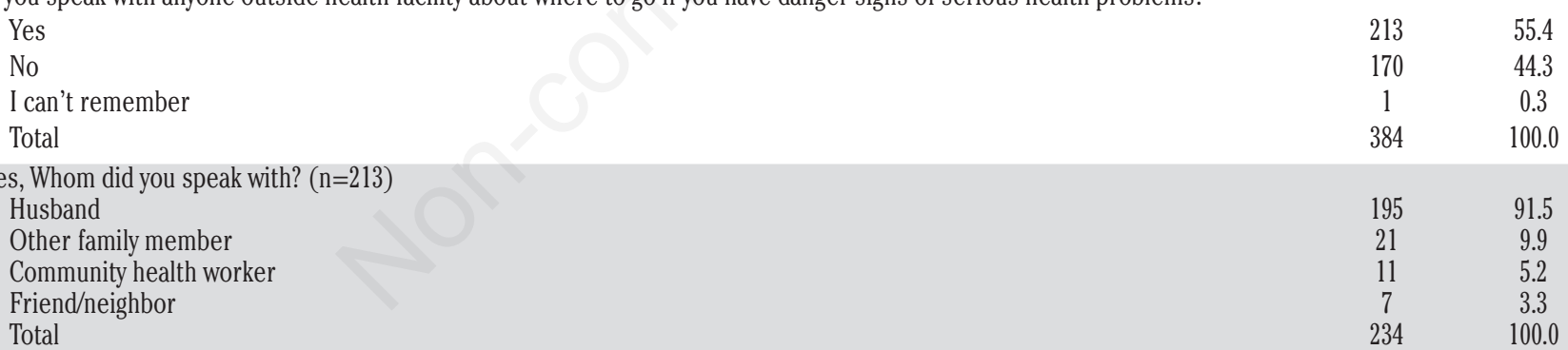

Table 4. Cross tabulation between parity, age group and knowledge of obstetric danger signs.

\begin{tabular}{|c|c|c|c|c|}
\hline \multirow[t]{2}{*}{ Variable } & \multicolumn{4}{|c|}{ Knowledge of obstetric danger signs } \\
\hline & Present (\%) & Absent (\%) & Total (\%) & Test of association \\
\hline \multicolumn{5}{|l|}{ Parity } \\
\hline $0-1$ & $80(20.3)$ & $56(14.2)$ & $136(34.5$ & \\
\hline$\geq 2$ & $206(52.3$ & $52(13.2)$ & $258(65.5)$ & $\chi^{2}$ \\
\hline Total & $286(72.7)$ & $108(27.4)$ & $394(100.0)$ & $\mathrm{P}=0.000$ \\
\hline \multicolumn{5}{|c|}{ Age group (years) } \\
\hline $16-24$ & $107(27.2)$ & $51(13.0)$ & $158(40.2)$ & \\
\hline $25-29$ & $56(14.2)$ & $26(6.6)$ & $82(20.9)$ & \\
\hline $30-34$ & $78(19.8)$ & $15(3.8)$ & $93(23.7)$ & \\
\hline $35-39$ & $31(7.9)$ & $12(3.1)$ & $43(10.9)$ & P(Fischer's $)=0.017$ \\
\hline $40-44$ & $14(3.6)$ & $2(0.5)$ & $16(4.1)$ & \\
\hline $45-49$ & $0(0.0)$ & $1(0.3)$ & $1(0.3)$ & \\
\hline Total & $286(72.8)$ & $107(27.2)$ & $393(100.0)$ & \\
\hline
\end{tabular}


poverty might be associated with this late antenatal booking.

Knowledge of obstetric danger signs during pregnancy, labor and post-partum is the first essential step for appropriate and timely referral. In this study, $77.1 \%$ of the respondents demonstrated knowledge of obstetric danger signs. This is similar to the findings of a study conducted in India $(79.2 \%)^{10}$ and Kenya (67\%). ${ }^{11}$ These findings are in contrast to the findings in South western Uganda, ${ }^{12}$ and South Africa ${ }^{13}$ where only $52 \%$ of the participants knew at least one danger sign. A few number of the respondents mentioned reduced fetal movement as a danger sign which was low, and similar to a study in Karachi ${ }^{14}$ where only $5 \%$ mentioned reduced fetal movement as a danger sign in pregnancy.

In this study, more than half of the respondents $(61.6 \%)$ reported bleeding as the most known danger sign during pregnancy. Other danger signs mentioned were severe headache $(32.5 \%)$, and convulsion (33.6\%). A similar pattern of danger signs awareness during pregnancy (bleeding $(83.5 \%)$; headache $(24.5 \%)$ and convulsion $(5.7 \%))$ was reported by Bililign and in Ethiopia. ${ }^{15}$

Key danger signs during labor and childbirth are severe vaginal bleeding, convulsions, prolonged labor, and retained placenta. In this study, convulsion $(49.0 \%)$, severe bleeding $(41.3 \%)$, and severe headache $(23.0 \%)$ were mentioned. Amenu et al. ${ }^{16}$ reported a similar pattern in Egypt. Key danger signs during post-partum period are severe bleeding following child birth, convulsions, loss of consciousness, and fever. In this study, $20.8 \%$ of the respondents knew severe bleeding as a danger sign post-partum. This is similar to the figure of $23.2 \%$ reported in Tanzania. ${ }^{17}$

Severe bleeding was the most frequently mentioned danger sign in pregnancy, labor and post-partum as seen above. The reason is most likely because it is the most visible obstetric danger sign, and the highest cause of maternal death immediately after delivery. ${ }^{18}$

This study revealed that more than half of respondents were advised by a health professional on danger signs during pregnancy, child birth and post-partum $(63.3 \%)$, where to deliver their baby $(63.5 \%)$ and where to go when danger signs occur (64.1\%). However, a few were advised on finance $(48.3 \%)$, transportation $(44.3 \%)$, and blood donor $(43.3 \%)$. This shows there is still need for the health workers to put more emphasis in addressing the issues of funds, transportation and blood donation during health talk at antenatal clinics. In a survey conducted in 19 sub Saharan Africa countries, it was concluded that there was high level of unmet needs for information on pregnancy complication in sub Saharan Africa particularly among those who face significant barrier to accessing care if complication occurs. ${ }^{19}$ In this study, half of the respondents were advised outside the health facility on danger signs $(50.5 \%)$; where to go when danger signs occur $(55.5 \%)$; where to give birth $(63.5 \%)$; arrangements for funds $(48.3 \%)$; and arrangement for blood donor $(43.3 \%)$.

The study showed that knowledge of obstetric danger signs was statistically associated with parity and age group $(\chi 2=19.778, \mathrm{P}=0.000 ; \mathrm{P}$ (Fischer's') $=0.017$ respectively).This was similar to the findings in Tanzania where knowledge of obstetric danger signs was statistically associated with multiparity, ${ }^{20}$ and in Egypt where awareness of obstetric danger signs was related to younger age and parity. ${ }^{21}$

\section{Conclusions}

The study findings generally revealed that there was awareness of obstetric danger signs. Vaginal bleeding was the commonest obstetric danger sign known.

The study also revealed that knowledge of obstetric danger signs was statistically associated with parity and age group.

\section{Recommendations}

The government should employ more health workers, most importantly, skilled birth attendants so that appropriate time should be allocated for proper health talk and counseling on the importance of early antenatal booking and awareness of other danger signs in pregnancy, labor and early puerperium.

\section{References}

1. Markos D, Bogale D. Birth preparedness and complication readiness among women of child bearing age group in Goba woreda, Oromia region, Ethiopia. BMC Pregnancy Childbirth 2014;14:19.

2. Thaddeus S Maine D. Too far to walk: maternal mortality context. Soc Sci Med 1994;38:1091-10.

3. Moran A, Sangli G, Dineen R, et al. Birth-preparedness for maternal health: Findings from Koupéla district, Burkina Faso. J Heal Popul Nutr 2006;24:48997.

4. Hiluf M, Fantahun M. Birth Preparedness and Complication Readiness among women in Adigrat town, north Ethiopia. Ethiop J Heal Dev 2007;22:14-20.

5. Roxana C, Barco D. Monitoring birth preparedness and complication readiness: tools and indicators for maternal and newborn health. JHPIEGO 2004:261.

6. Galadanci H, Ejembi C, Iliyasu Z, et al. Maternal health in Northern Nigeria - A far cry from ideal. BJOG An Int J Obstet Gynaecol 2007;114:448-52.

7. Onoh R, Umeora O, Agwu U, et al. Pattern and Determinants of Antenatal Booking at Abakaliki Southeast Nigeria. Ann Med Health Sci Res Internet 2013;3:132.

8. Ekele BA. Gestational age at antenatal clinic booking in Sokoto, northern Nigeria. J Med Sci 1998;27:161-3.

9. Adewunmi A, Rabiu K, Tayo A. Gestational age at antenatal booking in Lagos south west Africa. Int J Gynecol Obstet 2009;12.

10. Agarwal S, Sethi V, Srivastava K, et al. Birth preparedness and complication readiness among slum women in inore city, India. J Heal Popul Nutr 2010;28:383-91.

11. Mutiso S, Qureshi Z, Kinuthia J. Birth preparedness among antenatal clients. East Afr Med J 2008;85:275-83.

12. Kabakyenga J, Östergren P, Turyakira E, Pettersson K. Knowledge of obstetric danger signs and birth preparedness practices among women in rural Uganda. Reprod Health Internet 2011;8:33.

13. Hoque M, Hoque ME. Knowledge of danger signs for major obstetrics complication among pregnant Kwazulu Natal women: Implication of health education. Asia Specif J Publ Health 2011;23:946-56.

14. Hasan I, Nisar N. Women' Perceptions regarding Obstetric Complications and Care in a Poor Fishing Community in Karachi. J Pakistani Med Assoc 2002;52:1-9.

15. Bililign N, Mulatu T. Knowledge of obstetric danger signs and associated factors among reproductive age women in Raya Kobo district of Ethiopia: A community based cross-sectional study. BMC Pregnancy Childbirth 2017;17:17.

16. Amenu G, Mulaw Z, Seyoum T, Bayu H. Knowledge about Danger Signs of Obstetric Complications and Associated Factors among Postnatal Mothers of Mechekel District Health Centers, East Gojjam Zone, Northwest Ethiopia, 2014. Scientifica (Cairo) 2016;2016:17.

17. Pembe A, Urassa D, Carlstedt A, et al. 
Rural Tanzanian women's awareness of danger signs of obstetric complications. BMC Pregnancy Childbirth 2009;9:1-8.

18. WHO. Standards for Maternal and Neonatal Care. 2007.

19. Nikiéma B, Beninguisse G, Haggerty J. Providing information on pregnancy complications during antenatal visits: unmet educational needs in sub-Saharan Africa. Heal Policy Plan Internet 2009;24:367-76.

20. Magoma M, Requejo J, Campbell O, et al. High ANC coverage and low skilled attendance in a rural Tanzanian district : a case for implementing a birth plan intervention. BMC Pregnancy
Childbirth 2010;10:1-12.

21. Rashad W, Essa R. Women' Awareness of Danger Signs of Obstetrics Complications. J Am Sci 2010;6:1299306. 